abdomen the lumen of the bowel was somewhat larger than normal instead of being smaller. If the atrophy caused by this button is such that we do not get contraction by anastomosis, why should we expect to find it?

Dr. A. J. OchsNer of Chicago-This Section is fortunate in receiving the reports of Dr. Mayo's cases, as he is situated where he can have an enormous amount of material. In many cases the cicatricial stenosis occurring in acute conditions has not been overcome and there is still a certain amount of irritation there which is the cause of considerable tenderness. Whenever there is tenderness over any point of the abdominal cavity the muscles over this point will contract and one will therefore find a distinct tumor in many cases, simply from the contraction of the muscle. In a number of instances I have seen tumors diagnosed absolutely, before the anesthetizing of the patient, which could not be distiguished after the muscles had been relaxed, notwithstanding that the technique of the examination was as perfect as possible. We should not therefore make a positive diagnosis of carcinoma.

\section{SOME ADDITIONAL FACTS RELATING TO SKIN GRAFTING.}

Read in the Section on Surgery and Anatomy at the Forty-eighth Annual Meeting of the American Medical Association held at Philadelphia, Pa., June 1-4, 1897.

BY Z. J. LUSK, M.D.

WARSAW, N. Y.

At the meeting of the New York State Medical Association, held Oct. 15 and 17, 1896, I read a paper the title of which was "The Vitality of Cutaneous Epithelium After Its Separation from the Body." Believing the subject of great surgical importance, and having additional testimony of interest, $\bar{I}$ decided to briefly submit my experience at this meeting.

The question of the "limit of vitality" of skin separated from the body has been the subject of a great deal of experimentation. The longest period of which I can find record is ninety-six hours, or four days. ${ }^{1}$

Experiments have been made ${ }^{2}$ to ascertain the vitality of skin removed from the cadaver. Skin grafting has been successfully done with epidermis removed from the thigh six hours after death. Skin taken from amputated ${ }^{3}$ limbs has been found to make good material. After numerous trials, thirty-six hours was found to be the limit of vitality. These experiments are of importance no farther than demonstrating that cutaneous epithelium possesses great vitality, but beyond this fact, they are of no practical value with "the limit of vitality" terminating at thirtysix or even ninety-six hours.

The cuticle or external layer of the skin removed so that it includes only the epidermis and Malpighian layer is the material used in skin grafting, and I have found that their viability depends not upon the low temperature nor confined air, but solely and absolutely upon the elimination of all moisture. This discovery renders the foregoing experiments of value, offering a source whence material could be obtained. Great care is, under these circumstances, necessary in separating the cuticle. I would prefer the epidermis obtained by vesication with cantharis to any other method, as the cuticle is more perfectly separated, requiring only from two to four hours, more often about three hours, drying quickly at ordinary temperature after its removal; and if kept free from moisture it will retain its vitality for an indefinite period, being always ready for use. I shall briefly refer to cases of which a full description can be found in various peri-

1 Encyclopedia of Surgery, Vol, i, p. 543.

3 Medical Recore, Vol. xxt, p. 483 . odicals giving technique, etc., considering in this paper only the dates of operating, illustrating length of time intervening between dates of removal of cuticle and their successful employment in skin-grafting.

An important change in the manner of applying grafts has been made which simplifies the operation and removes the cause which may have led to failure by applying the wrong surface of the graft. Grafts are now applied $d r y$ and not moistened before using on account of the curling up of the edges, making it difficult of planting, failure resulting from applying the wrong surface of graft to granulation. By the method above described, equally good results follow and this danger is avoided. The following cases are given without history or detail, but only to show the date of injury, skin-grafting, and of recovery.

Case 1.--E. S., saltlifter, injured by falling into a pan of boiling brine, Jan. 14, 1895. Nearly eight hundred square inches of raw granulating surface on body. I began skingrafting February 16, using the dried epidermis, separated by vesication, adhering by one edge to body. He did nicely, whole surface healed and he was able to be up and about by April 1 .

Case 2.-M. C., scalded Dec. 3, 1895. December 26 I began skin grafting, using dried skin which had been separated twenty-three days from cutis by vesication. At date of skingrafting I removed several pieces of the dried skin, placed them between sterilized gauze and borated cotton, careful to note surface, tucked into envelope, labeled with date of separation from cutis, Dec. 3,1895 , and placed in office desk.

Case 3.-F. H., raw granulating surface two by two and onehalf inches on dorsal surface of foot. Did skin-grafting with the dried skin which was removed as stated, Dec. 3, 1895; grafts took nicely and patient was up and about February 5.

Case 4.-J. O., switchman, hand crushed between drawheads April 2. Did skin-grafting May 15. There was a large granulating surface on dorsal aspect of right hand. Used same material heretofore described. Development of grafts was vigorous and rapid so that one month later the surface had a good substantial epithelium covering.

Case 5.-July 20, Mrs. S., widow, aged 52, carcinoma of left breast, which was atrophied and adherent, while nipple appeared as if pushed up; it was large and indurated. Commencing above the nipple there was an ulcerated surface extending upward and inward two and one-half inches and one and three-fourths inches. Commenced using mixed toxins with no perceptible change for three months, when she began to improve in general health, gained in flesh and spirits, and by January, 1897, the ulcerated surface appeared more like healthy granulation, and had slightly diminished in size.

On February 9, Dr. Mann assisting, I used the remainder of material separated now over one year, and skin-grafted. Did not disturb proximal dressing for ten days, at which date there was no discharge. Dressings were moistened with balsam, peru mixture and six days later all the dressings were removed. To my surprise grafte had taken well and were doing nicely, except at lower surface where no evidence of epithelium appeared; ten days later, except a surface one-fourth inch square, all was doing nicely and covered with skin, which at each examination appeared more vigorous. About the month of March she was seized with a severe attack of rheumatism and was unable to leave her bed. I was obliged to suspend treatment. Two weeks later, April 1, the lower granulating surface began to extend its boundaries, destroying the new skin.

The longest period that the cuticle has been made to live and grow after removal from the body was ninety-six hours, or four days. This was an experiment made by Georges Martin, who believed that the prolonged vitality was due to the low temperature and confined air at which it was kept. I am of the opinion that its vitality was due to its being dry, or so nearly so as to prevent molecular change.

The cases reported by me show that in case No. 1 the material used had been separated from the cutis forty-eight days. In No. 2 it was separated twentythree days. In No. 3 the skin was taken from No. 2 ,

4 Medical Record; Journal American Medical Association; International Journal of Surgery. 
separated by vesication from scalding, and sterilized on December 26 , then covered with borated cotton and laid away in an office desk, when skin-grafting was done Jan. 12, 1896, forty days after separation from the cutis. No. 4 was with the same material, 164 days. No. 5 was the same as No. 3 and 4, grafts revitalized, showing as rapid and vigorous growth as in any of preceding cases, 418 days after its separation from cutis.

To conclude then this method should supersede all othors because of the following facts:

1. The surgeon can always have an abundance of material ready for immediate use, and the artificial skin produced is more firm and elastic than that produced by any other method.

2 . The cuticle when first removed should be sterilized, when it will soon become dry at ordinary tem. perature, care being taken to remove all folds or wrinkles and that it be kept entirely free from moisture.

3. The granulating surface should be thoroughly irrigated with warm normal salt or boric acid solution before applying grafts.

4. Grafts should not be moistened before being used, but should be dry, and great care should be taken that the proper surface be applied. Operator catching skin with common artery forceps, a piece can be clipped off one-twelfth inch wide and one inch in length, out of which twelve grafts should be made not more than one-half inch apart.

5. The grafted surface should be covered with sterilized gauze saturated with a mixture of balsam peru and castor oil, one drachm to one ounce, over which should be laid sterilized borated cotton, three to four layers.

6. Proximate dressing should not be disturbed under ten to fifteen days, unless pus is being formed, when it should be removed and carefully irrigated with boric acid solution, and new dressings applied. DISCUSSION,

Dr. George M. Sternberg of Washington-I would like to ask if Dr. Lusk ever used the skin from a blister produced by heat. It is very remarkable that the heat does not destroy the cuticle, and I think it would be important to determine the death point of the epithelial cells. I would suggest that if practicable some one might make this experiment.

Dr. R. H. SAYRE of New York-I am somewhat surprised at the vitality of living tissues exposed to dry hot air. In the treatment of chronic arthritis, in exposing joints to a bigh grade of air the skin will endure from 350 to 400 degrees $\mathrm{F}$. and I did not suppose this possible. Some persons can not stand more than 180 to 220 degrees. It occasionally happens, however, that after the lapse of a few days you will find ulcerated spots on the skin which look like a blister. Apparently this intense heat will at certain spots cause sloughing of the tissues, which is very slow in regenerating.

Dr. Thomas H. MANLey of New York-I hope we do not understand Dr. Lusk to say that this species of grafting was recommended to supplant skin-grafting proper, as this is really epidermal grafting. I presume he intends this method for superficial destruction of the layers of the integument. $\mathrm{He}$ would not recommend it, I should think, in that class of cases where the skin is entirely swept away. This method is similar to the Thiersch method and the only questions that will arise are as to how durable it is and as to whether there is any tendency to the scar formation which is so common in the Thiersch method. In parts of the body covered by the garments, where there is not much motion, I can understand that the plan sug gested by Dr. Lusk is probably better than any other. It is most extraordinary to conceive of the simplicity of it, and the fact that we are able to keep the tissues so long renders it one of the most valuable methods of skin-grafting that we have. How far can this layer of the epidermis supply this loss of skin is the point. In extensive injuries to limbs there are two important questions: First, what can we do in the destruc tiod of bone; and second, what can we do where there is not much destruction of bone, but there is much destruction of the skin. I would like to ask if, where there has been an extensive area of gangrene of the integument, this method would apply.

Dr. Lusk-Dr. Manley may be right, but his method would be called plastic surgery. In all the works that I have con. sulted skin. grafting is the only term used. I do not know of any heat that will hurt the skin except the heat that destroys the entire skin, such as boiling in a salt solution. My own experience was with a man who had plunged head first into a bin containing boiling brine. Four weeks after the accident I decided to commence skin.grafting and it was successful in every way. Dr. Roswell Park saw it and paid me a very high compliment for the discovery. The legs, arms, and a part of the body were skinned, and from seven to eight hundred inches were necessary to do the operation. I soaked the material in a peroxid solution and then applied it. So far as cicatricial contraction is concerned there were only a few corrugated bands. There were two ulcers, due to a slough, which healed entirely.

\section{DIAGNOSIS OF MINOR PHYSICAL INJURIES AND THEIR RELATION TO ACCIDENT INSURANCE ASSOCIATIONS (WITH ILLUSTRATIONS OF CASES).}

Presented to the Section on Surgery and Anatomy, at the Forty-eighth Annual Meeting of the American Medical Association held at Philadelphia, June 1-4, 1897.

BY LISTON H. MONTGUMERY, M.D. CHICAGO.

Accident insurance and personal injuries to policyholders, are subjects to which I have devoted some thought and attention during the past few years, and I am a staunch advocate of the former. As a rule, the reasonableness of its cost should commend itself to every worthy male adult subject who is eligible to avail himself of the privilege of procuring a certificate of membership in some one or more of the various substantial insurance associations throughout the country.

The business of accident insurance companies is mainly conducted by the secretary and a board of directors, and in the matter of claims, by the claims committee aided by the wisdom and advice of the surgeon, the medical director or medical examiner. The office that the surgeon fulfils is a most important one; one whose motive power and influence usually commands great respect from his business associates. To him is oftentimes referred questions that are more or less intricate on account of their not being understood by the board of direc. tors or claims committee, and this, according to my experience, is much more frequently the case when, as the title of this paper suggests, the injuries appear to be trivial or insignificant in character, notwithstanding the report of the attending physician or surgeon would indicate that just the opposite is the case.

Personal injuries are as varied in kind, character and degree as the kaleidoscopic changes in a man's lifetime and the causes producing them are as innumerable as it is possible to imagine. It is not to be wondered at, therefore, if a scientific descriptive report of an injury to a patient by the attending physician should require additional explanation or elucidation by the company's surgeon. In other words, without the aid or advice of a company's medical representative, it would not be possible to adjust and dispose of all cases of bodily injury in a satisfactory manner, and diplomacy of an honorable character is necessary in some instances to achieve this much desired result.

The declaration or blank form of application which 